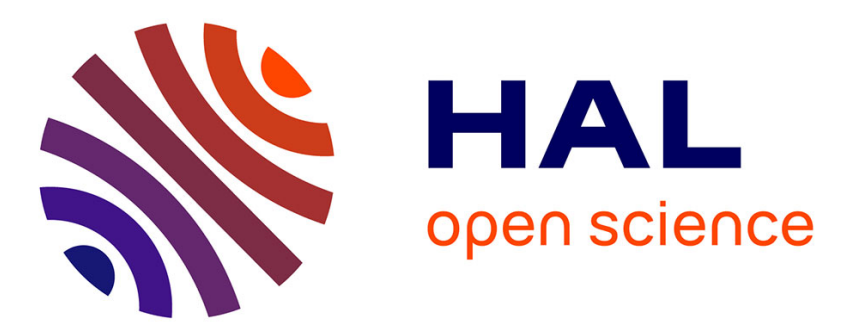

\title{
Reactions of antioxidants with molecular oxygen. Part III: Influence of phenolic stabiliser structures on their oxidation in an inert matrix
}

R. Navarro, Ludmila Audouin, Jacques Verdu

\section{- To cite this version:}

R. Navarro, Ludmila Audouin, Jacques Verdu. Reactions of antioxidants with molecular oxygen. Part III: Influence of phenolic stabiliser structures on their oxidation in an inert matrix. Polymer Degradation and Stability, 2011, 96 (7), pp.1389-1396. hal-02456068

\section{HAL Id: hal-02456068 \\ https://hal.science/hal-02456068}

Submitted on 27 Jan 2020

HAL is a multi-disciplinary open access archive for the deposit and dissemination of scientific research documents, whether they are published or not. The documents may come from teaching and research institutions in France or abroad, or from public or private research centers.
L'archive ouverte pluridisciplinaire HAL, est destinée au dépôt et à la diffusion de documents scientifiques de niveau recherche, publiés ou non, émanant des établissements d'enseignement et de recherche français ou étrangers, des laboratoires publics ou privés. 


\title{
Reactions of antioxidants with molecular oxygen. Part III: Influence of phenolic stabiliser structures on their oxidation in an inert matrix
}

\author{
R. Navarro*, L. Audouin, J. Verdu \\ Arts et Métiers ParisTech, CNRS, PIMM, 151 boulevard de l'Hôpital, 75013 Paris, France
}

A R T I C L E I N F O

Keywords:

Phenolic antioxidant

Thiobisphenol antioxidant

Thermal oxidation

Kinetics

SEC

\begin{abstract}
A B S T R A C T
The oxidation of five different phenolic antioxidants in inert substrates has been investigated varying the temperature and oxygen pressure conditions. The stabiliser consumption in this reaction has been quantified by steric exclusion chromatography. The tendency of the variation of the residual antioxidant concentration with exposure time in the presence of oxygen shows a simple apparent first order process in all cases. The kinetic parameters were determined applying this simple kinetic model. The influence of structural characteristics of stabilisers under study on kinetic parameters of the direct reaction with the oxygen has been analysed. On the other hand, the information obtained about reaction products generated for each antioxidant helped us to explain the results obtained.
\end{abstract}

\section{Introduction}

Polymer stabilisation by hindered phenols $(\mathrm{AH})$ has generated an abundant literature in the past half century [1-5]. It is well established that abstraction of the phenolic hydrogen by a peroxy radical is a key reaction:

(VII) $\mathrm{POO}^{\bullet}+\mathrm{AH} \rightarrow \mathrm{POOH}+\mathrm{A}^{\bullet}$

Here, $A^{\bullet}$ is a phenoxy radical unable to propagate the oxidation radical chain. Reaction (VII) competes with the propagation of polymer oxidation:

(III) $\mathrm{POO}^{\bullet}+\mathrm{PH} \rightarrow \mathrm{POOH}+\mathrm{P}^{\bullet}$

In a first approach, it can be assumed that, to be efficient, the event must have a rate $r_{7}$ of the same order of magnitude as propagation rate $r_{3}$ or higher. This condition can be described by:

$\frac{r_{7}}{r_{3}}=\frac{k_{7}\left[\mathrm{POO}^{\circ}\right][\mathrm{AH}]}{k_{3}\left[\mathrm{POO}^{\circ}\right][\mathrm{PH}]} \geq 1$

i.e.

* Corresponding author. Tel.: +331442463 07; fax: +33144246382.

E-mail addresses: rosa.navarro@paris.ensam.fr, rosa.navarro@ua.es (R. Navarro), ludmila.audouin@paris.ensam.fr (L. Audouin). $\frac{k_{7}}{k_{3}} \geq \frac{\mathrm{PH}}{\mathrm{AH}} \geq 1$

For technical (limited solubility) as well as for economical reasons, stabilisers are used in concentrations generally lower than $10^{-2} \mathrm{~mol} \mathrm{l}^{-1}$. In common hydrocarbon polymers, the concentration of active hydrogen $([\mathrm{PH}])$ is generally higher than $10 \mathrm{~mol} \mathrm{l}^{-1}$, so that the condition for stabiliser efficiency would be, roughly:

$\frac{k_{7}}{k_{3}} \geq 1000$

This reasoning is, no doubt, an oversimplification as will be seen below, but it stresses the interest of a knowledge of the reactivity of these stabilisers in hydrogen abstraction reactions.

These reactions are not very easy to study in oxidizable substrates because they coexist with other reactions, especially those involving a cyclohexadienonyl radical $\mathrm{B}^{\bullet}$ resulting from isomerization of the phenoxy radical:

(VIII) $\mathrm{A}^{\bullet} \rightarrow \mathrm{B}^{\bullet}$

(IX) $\mathrm{POO}^{\bullet}+\mathrm{B}^{\bullet} \rightarrow$ inactive products

$\left(\mathrm{X}_{\mathrm{a}}\right) \mathrm{B}^{\bullet}+\mathrm{B}^{\bullet} \rightarrow$ dimerisation

$\left(\mathrm{X}_{\mathrm{b}}\right.$, etc.) $\mathrm{B}^{\bullet} \rightarrow$ oligomerisation and other reactions 
Table 1

Code, chemical name, commercial name, molar mass and concentration used in kinetic investigation.

\begin{tabular}{cllll}
\hline Code & Chemical name & $\begin{array}{l}\text { Commercial } \\
\text { name }\end{array}$ & $\begin{array}{l}\mathrm{M}_{\mathrm{w}} \\
\left(\mathrm{g} \mathrm{mol}^{-1}\right)\end{array}$ & $\begin{array}{l}\text { Concentration } \\
\left(\mathrm{mol} \mathrm{l}^{-1}\right) \times 10^{3}\end{array}$ \\
\hline AO1 & $\begin{array}{l}\text { 2,2'-Thiobis } \\
\text { (6-tert-butyl-p-cresol) }\end{array}$ & Irganox 1081 358.5 & 4.75 \\
$\mathrm{AO2}$ & $\begin{array}{l}\text { 5-Tert-butyl-4-hydroxy-2 } \\
\text {-methylphenyl sulphide }\end{array}$ & Irganox 415 & 358.5 & 8.43 \\
$\mathrm{AO3}$ & $\begin{array}{l}\text { 4,4'-Butylidenebis } \\
\text { (6-tert-butyl-m-cresol) }\end{array}$ & 382.6 & 5.63 \\
$\mathrm{AO4}$ & $\begin{array}{l}\text { Isooctyl-3-(3,5-di-tert-butyl-4 } \\
\text {-hydroxyphenyl)propionate } \\
\text { 2,2'-Methylene-bis } \\
\text { (4-methyl-6-tert-butylphenol) }\end{array}$ & Irganox 1135 390.6 & 17.4 \\
\hline & Irganox 2246 340.5 & 5.99 \\
\hline
\end{tabular}

In certain circumstances, with certain phenols [6] and probably with all phenols at high oxygen pressures [7], atmospheric oxygen is able to react by oxygen abstraction [8-10]:

$$
\text { (XI) } \mathrm{AH}+\mathrm{O}_{2} \rightarrow \mathrm{A}^{\bullet}+\mathrm{HOO}^{\bullet}
$$

In the ground state, the $\mathrm{O}_{2}$ molecule is a biradical considerably less reactive than an alkyl peroxy radical, but presumably obeying similar structure-reactivity relationships. A kinetic study is easier for the oxygen-stabiliser reaction than for the peroxy-stabiliser reaction provided that it is studied in a non-oxidizable solvent. As a matter of fact, the oxygen concentration can be precisely known whereas the concentration of peroxy radicals in an oxidizable substrate is difficult to determine except in rare cases where it can be determined by ESR. Furthermore, in oxidizable substrates, there are other reactive species eventually able to react with stabiliser molecules, for instance alkyl radicals or hydroperoxides. These latter species can play an important role in the case of thiobisphenols [11-14]. In the case of oxygen-stabiliser reactions in inert solvents, no sulphur-oxygen reactions are expected at moderate temperatures $\left(\leq 120^{\circ} \mathrm{C}\right)$, which is perhaps not the case at $200^{\circ} \mathrm{C}[1,15]$.

It seemed to us interesting to compare the reactivities towards oxygen of five commercial phenolic stabilisers among which were two isomeric thiobisphenols, two bisphenols having a hydrocarbon bridge and one common monofunctional phenol.

\section{Equipment and experimental procedure}

\subsection{Materials}

The stabilisers under study are listed in Table 1. AO1, AO2 and AO3 were supplied by Sigma Aldrich. AO4 and AO5 were supplied by Ciba SC. The antioxidant structures are shown in Fig. 1.

The chosen inert solvents were a polydimethylsiloxane oil (silicone) having a viscosity of $50 \mathrm{mPa} s$ at $25^{\circ} \mathrm{C}$ (DC 200 from Sigma Aldrich) and 1,2,4-trichlorobenzene (TCB from Sigma Aldrich), having a density of $1.454 \mathrm{~g} \mathrm{ml}^{-1}$ at $25^{\circ} \mathrm{C}$. The solubility coefficient of oxygen $\mathrm{S}_{\mathrm{O}_{2}}$ in silicone at $90^{\circ} \mathrm{C}$ was $4.92 \times 10^{-8} \mathrm{~mol}^{-1} \mathrm{~Pa}^{-1}[16] . \mathrm{S}_{\mathrm{O}_{2}}$ was not known in the case of TCB. As Richaud [17] it will be considered that from the point of view of oxygen solubility, TCB is not very far from benzene, for which $\mathrm{S}_{\mathrm{O}_{2}}=1.06 \times 10^{-8} \mathrm{~mol} \mathrm{l}^{-1} \mathrm{~Pa}^{-1}$ at $90^{\circ} \mathrm{C}$. Comparison of results obtained in both solvents are thus to be cautiously interpreted, but results obtained in both solvents with AO5 will give us an interesting orientation.

\subsection{Ageing conditions}

AO1, AO4 and AO5 are soluble in silicone oil, which makes the analysis by the analytical techniques used easier $[18,19]$. However, a<smiles>Cc1cc(Sc2cc(C)cc(C(C)(C)C)c2O)c(O)c(C(C)(C)C)c1</smiles>

C<smiles>CCCC(c1cc(C(C)(C)C)c(O)cc1C)c1cc(C(C)(C)C)c(O)cc1C</smiles>

e<smiles>Cc1cc(Cc2cc(C)cc(C(C)(C)C)c2O)c(O)c(C(C)(C)C)c1</smiles><smiles>Cc1cc(O)c(C(C)(C)C)cc1Sc1cc(C(C)(C)C)c(O)cc1C</smiles>

d<smiles>CCCCC(=O)OCCc1cc(C(C)(C)C)c(O)c(C(C)(C)C)c1</smiles>

Fig. 1. Structure of stabilisers studied: (a) AO1, (b) AO2, (c) AO3, (d) AO4 and (e) AO5. 


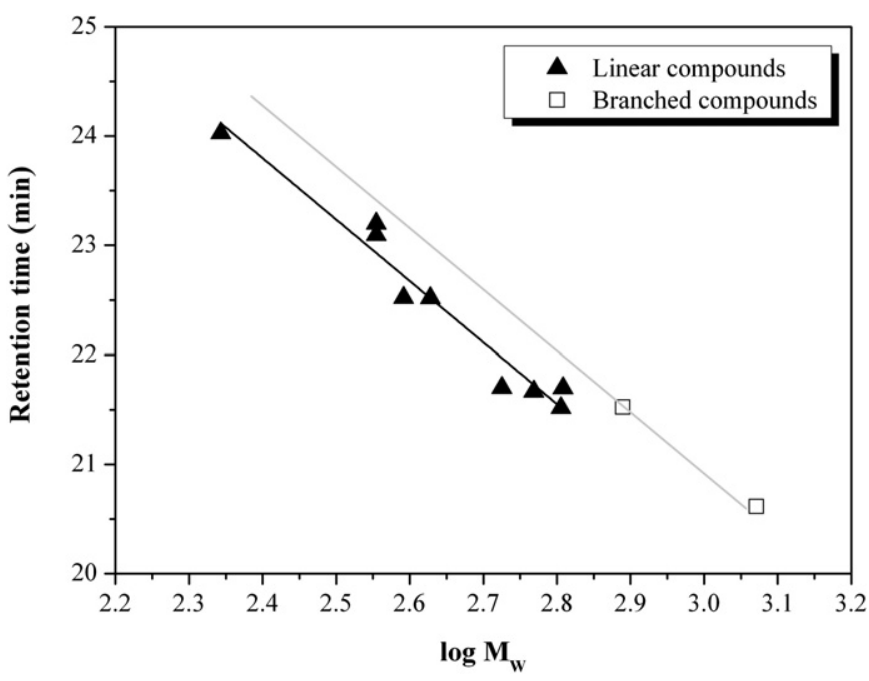

Fig. 2. Calibration curve for molar mass determination.

$\mathrm{AO} 2$ and $\mathrm{AO} 3$ antioxidants are insoluble in this substrate and, therefore, TCB was employed. The stabiliser concentrations used in ageing tests are given in Table 1 . For AO1, AO4 and AO5, ageing experiments were performed at $80,90,100$ and $110{ }^{\circ} \mathrm{C}$ under 3.0 MPa oxygen pressure. For all the stabilisers, experiments were performed at $90{ }^{\circ} \mathrm{C}$ and $3.0 \mathrm{MPa}$ oxygen pressure. The effect of oxygen pressure was studied only at $120{ }^{\circ} \mathrm{C}$ for AO1, AO4 [19] and AO5 [18].

\subsection{Analytical methods}

Initial stabilisers and their reaction products were analysed by steric exclusion chromatography (SEC). SEC was performed using a WATERS 714 chromatograph equipped with a photodiode array detector (PDA). Two columns were placed in series, HR1 and HR4E $(5 \mu \mathrm{m}, 4.6 \times 300 \mathrm{~mm})$ and maintained at $40{ }^{\circ} \mathrm{C}$. Tetrahydrofuran (THF) was used as mobile phase at a rate of $0.3 \mathrm{ml} \mathrm{min}^{-1}$. Each antioxidant sample was dissolved in $2 \mathrm{ml}$ of THF. In the SEC analysis of $\mathrm{AO} 2$ and $\mathrm{AO} 3$ antioxidants, where TCB was employed, the signal saturation caused by TCB from 25 min forced us to switch off SEC analysis. Therefore, it was impossible to observe the potential presence of compounds with lower molar masses than the residual stabiliser.

A calibration curve was built in order to determine the molar masses of reaction products. Various aromatic compounds (toluene

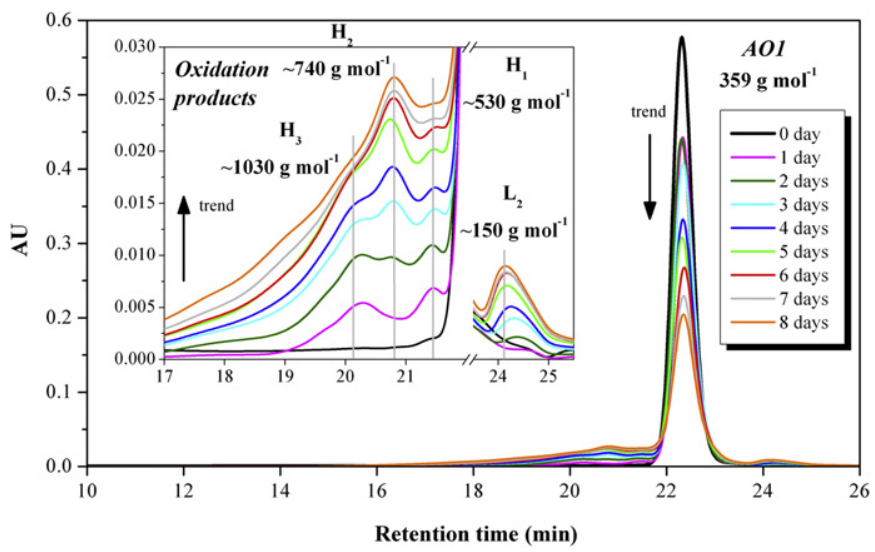

Fig. 3. SEC chromatograms of $A O 1$ acquired at $293 \mathrm{~nm}$ at various exposure times at $90{ }^{\circ} \mathrm{C}$ under 3.0 MPa oxygen pressure.

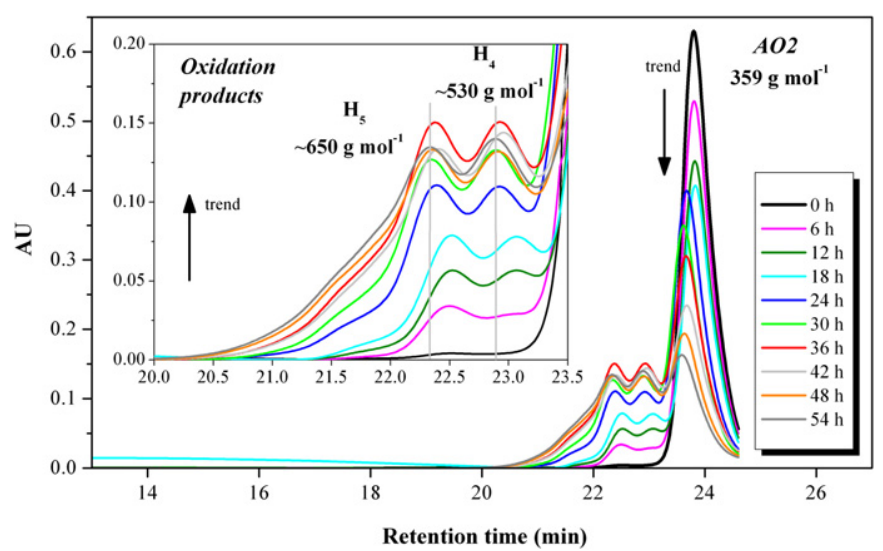

Fig. 4. SEC chromatograms of $\mathrm{AO} 2$ acquired at $283 \mathrm{~nm}$ at various exposure times at $90{ }^{\circ} \mathrm{C}$ under $3.0 \mathrm{MPa}$ oxygen pressure.

and xylene), phenolic antioxidants (ionol, Irganox 1520, Irganox 1076, Irganox 245, Irganox 259, Irganox 1035, Irganox 1330 and Irganox 1010) and, indeed, the five antioxidants under study (AO1, $\mathrm{AO} 2, \mathrm{AO} 3, \mathrm{AO} 4$ and AO5) were used as standards. The calibration curve is shown in Fig. 2. A different behaviour can be observed for the linear and branched compounds. The slope of straight lines is the same, varying the ordinate. The approximation of calculated molar masses from calibration straight line of linear compounds was better for oxidation products of low molar mass, while a better approximation was obtained for oxidation products of high molar mass when the calibration straight line of branched compounds was applied. This method is not precise enough to determine the exact molar mass value, but it allows to clearly distinguish between monomeric starting compounds and reaction products resulting from their degradation or from their oligomerisation.

\section{Results and discussion}

Examples of changes of chromatograms acquired at the wavelength of the initial antioxidant peak are shown in Fig. 3 (AO1), Fig. 4 (AO2), Fig. 5 (AO3), Fig. 6 (AO4) and Fig. 7 (AO5).

In all the cases one observes the progressive disappearance of the initial antioxidant peak and the growth of various species whose molar mass has been estimated using the calibration curve. The only exception is observed in the case of AO4 (Fig. 6), where a by-product having almost the same molar mass as AO4 interferes with AO4 peak. HPLC was used to achieve the complete separation between the residual antioxidant and its by-products [19]. The

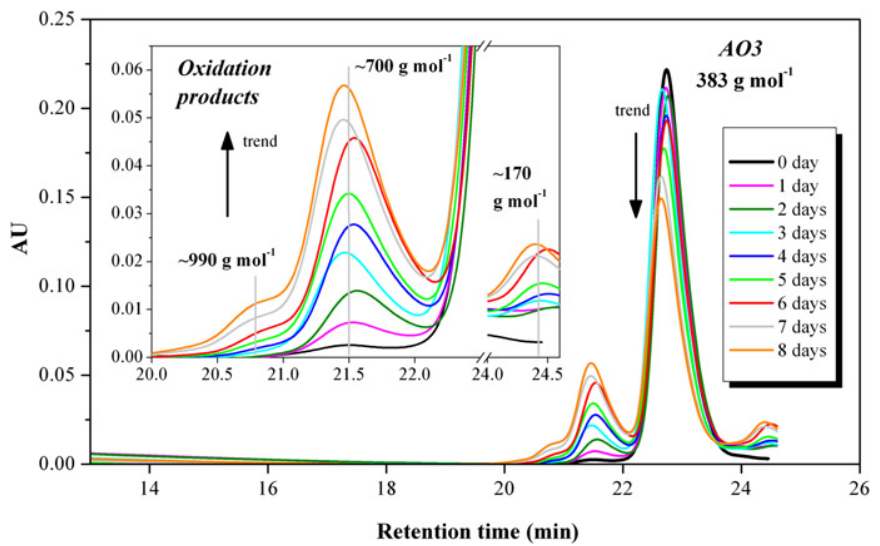

Fig. 5. SEC chromatograms of AO3 acquired at $281 \mathrm{~nm}$ at various exposure times at $90{ }^{\circ} \mathrm{C}$ under 3.0 MPa oxygen pressure. 


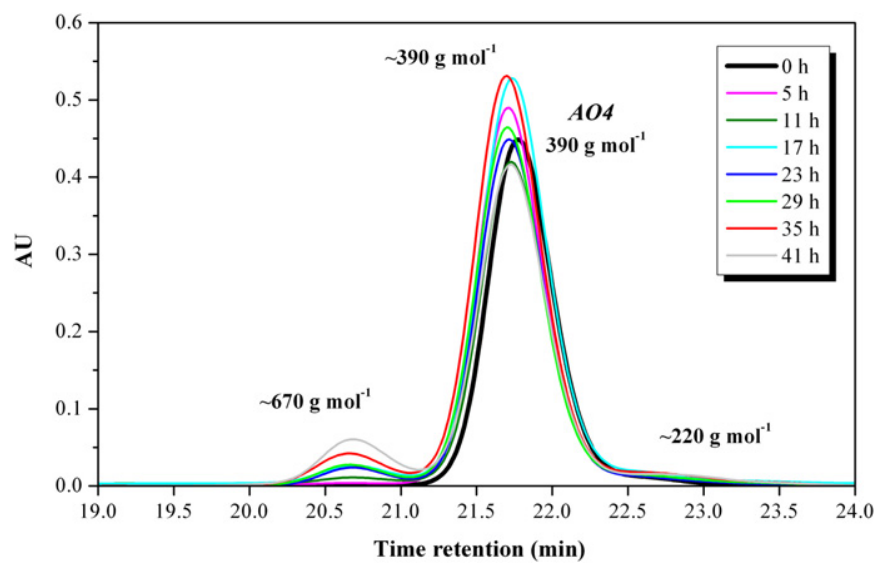

Fig. 6. SEC chromatograms of $\mathrm{AO} 4$ acquired at $276 \mathrm{~nm}$ at various exposure times at $90{ }^{\circ} \mathrm{C}$ under $3.0 \mathrm{MPa}$ oxygen pressure.

molar mass data are summarized in Table 2. It was not possible to identify precisely the oxidation products owing to the scatter of calibration curve, but the incertitude intervals are sharp enough to permit to determine the number of rings in the molecule.

For all the antioxidants under study, oxidation leads to coupling or oligomerisation products of molar mass higher than the initial stabiliser one. Pseudo dimeric species largely predominate in the case of thiobisphenol AO2 and monophenol AO4, whereas trimeric species or even larger molecules appear in the other bisphenolic antioxidants.

In many cases, reaction products of molar mass lower than the initial stabiliser one are formed. They can result from the breaking of the bisphenol bridge, for instance in the case of AO1 or from breaking of the aliphatic tail, for instance in the case of AO4. This later stabiliser has been the subject of a detailed study in the preceding part of this article [19]. It is partly transformed into cinnamate of which the molar mass $\left(388.6 \mathrm{~g} \mathrm{~mol}^{-1}\right)$ differs only slightly from AO4 one (390.6 $\mathrm{g} \mathrm{mol}^{-1}$ ), but with its UV/VIS absorption band bathochromically shifted from $276 \mathrm{~nm}$ to $311 \mathrm{~nm}$.

To clarify some eventual problems of peak overlapping in SEC chromatograms, we have recorded these latter with another detection wavelength, for instance at $418 \mathrm{~nm}$ for AO1 (Fig. 8) or at $398 \mathrm{~nm}$ for AO2 (Fig. 9). In the case of AO1, the chromatogram reveals the presence of a species of approximate molar mass $\sim 250 \mathrm{~g} \mathrm{~mol}^{-1}\left(\mathrm{~L}_{1}\right)$ which is totally transparent at $293 \mathrm{~nm}$ wavelength. The high molar mass products $\left(\mathrm{H}_{1}, \mathrm{H}_{2}, \mathrm{H}_{3}\right.$, etc) contain

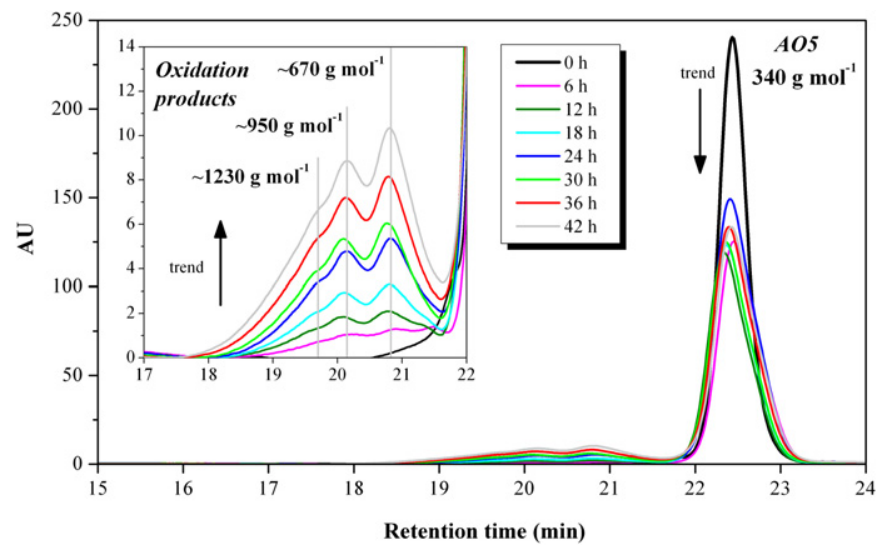

Fig. 7. SEC chromatograms of AO5 acquired at $280 \mathrm{~nm}$ at various exposure times at $90{ }^{\circ} \mathrm{C}$ under 3.0 MPa oxygen pressure.
Table 2

Summary of SEC results for the antioxidants under study.

\begin{tabular}{|c|c|c|c|c|}
\hline Antioxidant & $\begin{array}{l}\mathrm{RT} \text { in SEC } \\
(\mathrm{min})\end{array}$ & $\begin{array}{l}\mathrm{M}_{\mathrm{w}} \\
\left(\mathrm{g} \mathrm{mol}^{-1}\right)\end{array}$ & $\mathrm{M}_{\mathrm{w}} / \mathrm{M}_{\mathrm{w}} \mathrm{AO}$ & Possible attribution \\
\hline \multirow[t]{6}{*}{$\mathrm{AO1}$} & 20.3 & $\sim 1030-1080$ & $2.9-3.0$ & "Trimer" $[13,21]$ \\
\hline & 20.8 & $\sim 740-790$ & $2.1-2.2$ & "Dimer" $[13,21]$ \\
\hline & 21.4 & $\sim 530-560$ & $1.5-1.6$ & $\begin{array}{l}\text { Triphenolic } \\
\text { structures [22] }\end{array}$ \\
\hline & 22.3 & 358.5 & 1 & AO1 \\
\hline & 22.7 & $\sim 250-330$ & $0.7-0.9$ & $\begin{array}{l}\text { Sulphonic acid } \\
\text { derivative [13] }\end{array}$ \\
\hline & 24.1 & $\sim 150-190$ & $0.4-0.5$ & $\begin{array}{l}\text { 6-tert-butyl-4-methyl-1, } \\
\text { 2-benzoquinone [13] }\end{array}$ \\
\hline \multirow[t]{4}{*}{$\mathrm{AO} 2$} & 22.0 & $\sim 650-770$ & $1.8-2.1$ & "Dimer" \\
\hline & 22.5 & $\sim 510-640$ & $1.4-1.7$ & Triphenolic structures [22] \\
\hline & 23.3 & 358.5 & 1 & $\mathrm{AO} 2$ \\
\hline & 23.6 & $\sim 330-420$ & $0.9-1.2$ & Sulphoxide, sulphone [13] \\
\hline \multirow[t]{4}{*}{$\mathrm{AO} 3$} & 20.8 & $\sim 990-1090$ & $2.6-2.9$ & Oligomeric product \\
\hline & 21.5 & $\sim 700-810$ & $1.8-2.1$ & Oligomeric product \\
\hline & 22.7 & 382.6 & 1 & $\mathrm{AO} 3$ \\
\hline & 24.4 & $\sim 170-240$ & $0.4-0.6$ & Chain-breaking product \\
\hline \multirow[t]{4}{*}{$\mathrm{AO} 4$} & 20.6 & $\sim 670-820$ & $1.7-2.1$ & "Dimer" [19] \\
\hline & 21.7 & $\sim 400$ & 1.0 & AO4, cinnamate [19] \\
\hline & 22.9 & $\sim 220-320$ & $0.6-0.8$ & $\begin{array}{l}\text { Benzoquinone, } \\
\text { quinone methide [19] }\end{array}$ \\
\hline & 23.5 & $\sim 170-250$ & $0.4-0.6$ & Chain-breaking product [19] \\
\hline \multirow[t]{4}{*}{ AO5 } & 19.8 & $\sim 1230-1310$ & $3.6-3.9$ & "Tetramer" [18] \\
\hline & 20.3 & $\sim 950-1080$ & $2.8-3.2$ & “Trimer" [18] \\
\hline & 20.9 & $\sim 670-820$ & $2.0-2.4$ & “Dimer” [18] \\
\hline & 22.5 & 340.5 & 1 & AO5 \\
\hline
\end{tabular}

apparently the chromophore of $\mathrm{L}_{1}$ and the chromophore of the initial molecule since they are detected at $293 \mathrm{~nm}$ as well as at $418 \mathrm{~nm}$. Compared to the presumed "dimer" $\left(\mathrm{H}_{2}\right)$ and "trimer" $\left(\mathrm{H}_{3}\right)$, the species having an approximate molar mass of $\sim 530 \mathrm{~g} \mathrm{~mol}^{-1}$ $\left(\mathrm{H}_{1}\right)$ absorbs less at $293 \mathrm{~nm}$ and more at $418 \mathrm{~nm}$. There is a wide consensus on the attribution of the absorption at $\sim 400 \mathrm{~nm}$ to a quinone structure [20]. The fact that high molar mass species, i.e. mainly oligomers, contain both phenolic and quinone chromophores agrees with various literature proposals (Scheme 1) [13,21].

Such oligomeric species would be formed independently of the nature of the bisphenol bridge: sulphur (AO1) or methylene (AO5).

The only reasonable assignment for the species having an approximate molar mass of $\sim 530 \mathrm{~g} \mathrm{~mol}^{-1}\left(\mathrm{H}_{1}\right)$ seems to be a triaromatic compound resulting from first the rupture of the sulphur bridge in a thiobisphenol molecule (or one of its transformation products preserving the diaromatic character). Second the grafting of one monoaromatic compound resulting from this rupture to a thiobisphenol molecule (or to one of its transformation products

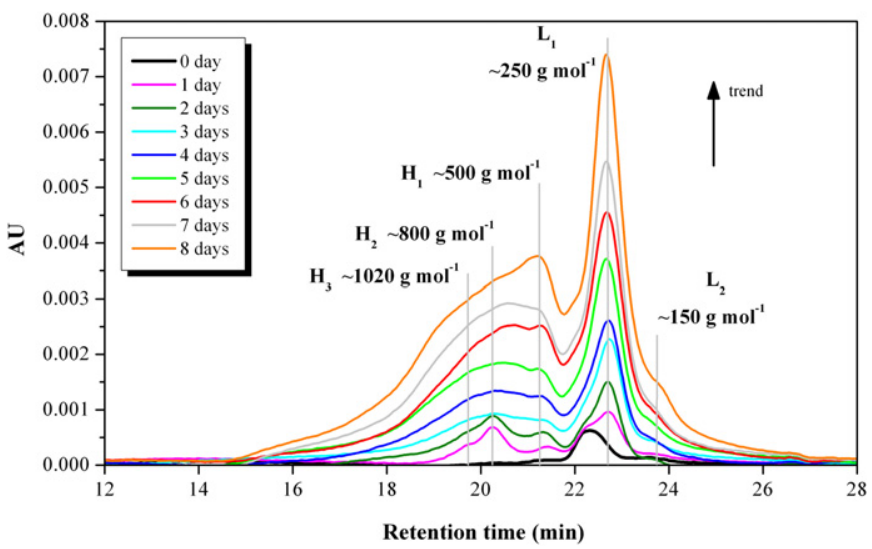

Fig. 8. SEC chromatograms of $A O 1$ acquired at $418 \mathrm{~nm}$ at various exposure times at $90{ }^{\circ} \mathrm{C}$ under 3.0 MPa oxygen pressure. 


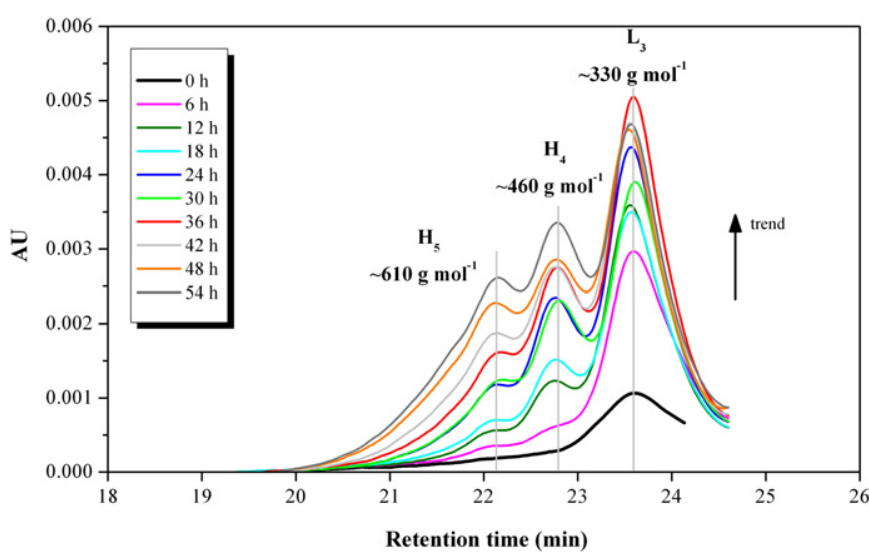

Fig. 9. SEC chromatograms of AO2 acquired at $398 \mathrm{~nm}$ at various exposure times at $90{ }^{\circ} \mathrm{C}$ under $3.0 \mathrm{MPa}$ oxygen pressure.

in which the diaromatic character has been preserved). According to UV data, this species would be more conjugated than "dimer" and "trimer" ones.

Such species were previously found by Uhniat et al. [22] which proposed a triphenolic structure (Scheme 2).

It is noteworthy that the formation of such molecules needs a complex set of splitting/recombination events. A comparison of AO1 chromatograms obtained at $293 \mathrm{~nm}$ (Fig. 3) and $418 \mathrm{~nm}$ (Fig. 8), clearly shows that the species of molar mass c.a. $530 \mathrm{~g} \mathrm{~mol}^{-1}$ contain the quinone chromophore, that disagrees with the structures of Scheme 2. These latter seem to result exclusively from a process in which the primary event would be the scission of the sulphur-carbon bond although we are not able to imagine a recombination process preserving the phenolic character of the molecule. Here, it seems reasonable to suppose that the primary event is exclusively, in all cases, the abstraction of the phenolic hydrogen by oxygen. In thiobisphenols, the resulting radicals would presumably rearrange (among other secondary processes), by splitting of the sulphur-carbon bond and formation of reactive fragments able to recombine with the starting antioxidant or one of its quinone derivatives. The product of molar mass c.a. $250 \mathrm{~g} \mathrm{~mol}^{-1}$ is presumably the mononuclear sulphonic acid derivative [13], that confirms the hypothesis of sulphur-carbon bond splitting.

In the case of $\mathrm{AO} 2$, the comparison of chromatograms acquired at $283 \mathrm{~nm}$ (Fig. 4) and $398 \mathrm{~nm}$ (Fig. 9) reveal the growth of a species having almost the same molar mass as the starting stabiliser, but almost transparent at its peak wavelength $(283 \mathrm{~nm})$. The distribution of high molar mass species differs significantly from AO1. The yield in molecules of high molar mass $\left(>700 \mathrm{~g} \mathrm{~mol}^{-1}\right)$ is considerably lower for $\mathrm{AO} 2$ than for AO1. But the main difference concerns low molar mass fraction. The molar mass of the main oxidation product is significantly higher for $\mathrm{AO} 2\left(\sim 330 \mathrm{~g} \mathrm{~mol}^{-1}\right)$ than for AO1 ( $\left.\sim 250 \mathrm{~g} \mathrm{~mol}^{-1}\right)$ and the species of lowest molar mass eluted for AO1 ( $\left.\sim 150 \mathrm{~g} \mathrm{~mol}^{-1}\right)$ does not appear for AO2.

All the observations made are summarized in Table 2 , in which "dimer", "trimer", etc mean molecules having about same molar mass as true dimers, trimers, etc. In fact this distinction can be justified as follows for bisphenols. There is a wide consensus in the literature to assume that the primary chemical act is always the abstraction of the phenolic hydrogen to give a phenoxy radical $\left(\mathrm{AR}^{*}\right)$ which isomerises easily into cyclohexadienonyl radical $\mathrm{CR}^{*}$ (Scheme 3).

The cyclohexadienonyl radical $\mathrm{CR}^{\bullet}$ can eventually evolve into another unspecified conjugated species but we will consider here, in the sake of simplicity, that the chemical evolution of a single phenolic group stops at $\mathrm{CR}^{\bullet}$ level. For a bisphenol having the bridge $\mathrm{Y}$, we can thus imagine three main types of diaromatic species: unreacted $(\mathrm{AH}-\mathrm{Y}-\mathrm{AH})$; monoreacted $\left(\mathrm{AH}-\mathrm{Y}-\mathrm{CR}^{*}\right)$ and direacted $\left(\mathrm{CR}^{\circ}-\mathrm{Y}-\mathrm{CR}^{*}\right)$. Supposing that the unreacted bisphenol is not directly reactive in coupling and oligomerisation processes, one can imagine the following combination for "dimers":

$$
\begin{aligned}
& A H-Y-C R-C R-Y-A H \\
& A H-Y-C R-C R-Y-C R^{\bullet} \\
& C R^{\bullet}-Y-C R-C R-Y-C R^{\bullet}
\end{aligned}
$$

And for "trimers":

$$
\begin{aligned}
& \mathrm{AH}-\mathrm{Y}-\mathrm{CR}-\mathrm{CR}-\mathrm{Y}-\mathrm{CR}-\mathrm{CR}-\mathrm{Y}-\mathrm{AH} \\
& \mathrm{AH}-\mathrm{Y}-\mathrm{CR}-\mathrm{CR}-\mathrm{Y}-\mathrm{CR}-\mathrm{CR}-\mathrm{Y}-\mathrm{CR}^{\bullet} \\
& \mathrm{CR}^{\bullet}-\mathrm{Y}-\mathrm{CR}-\mathrm{CR}-\mathrm{Y}-\mathrm{CR}-\mathrm{CR}-\mathrm{Y}-\mathrm{CR}^{\bullet}
\end{aligned}
$$

One can see that unreacted and reacted phenol moieties can coexist in "dimer" and "trimer" mixtures, that explains why these species absorb at both wavelengths characterizing respectively the initial stabiliser and its conjugated reaction product. These observations agree with previously found or hypothesized product structures. The main references for possible peak assignments are given in Table 2.

Let us now consider kinetic aspects. The rate of phenolic group consumption can be determined from the decrease of the stabiliser peak intensity assuming that at the beginning of exposure (at low conversion), the decrease of this peak is only due to the reaction:

$$
\mathrm{AH}-\mathrm{Y}-\mathrm{AH}+\mathrm{O}_{2} \rightarrow \mathrm{AH}-\mathrm{Y}^{-\mathrm{CR}^{\bullet}}+\mathrm{O}_{2} \rightarrow \mathrm{CR}^{\bullet}-\mathrm{Y}^{-} \mathrm{CR}^{\bullet}
$$

That is kinetically equivalent to:

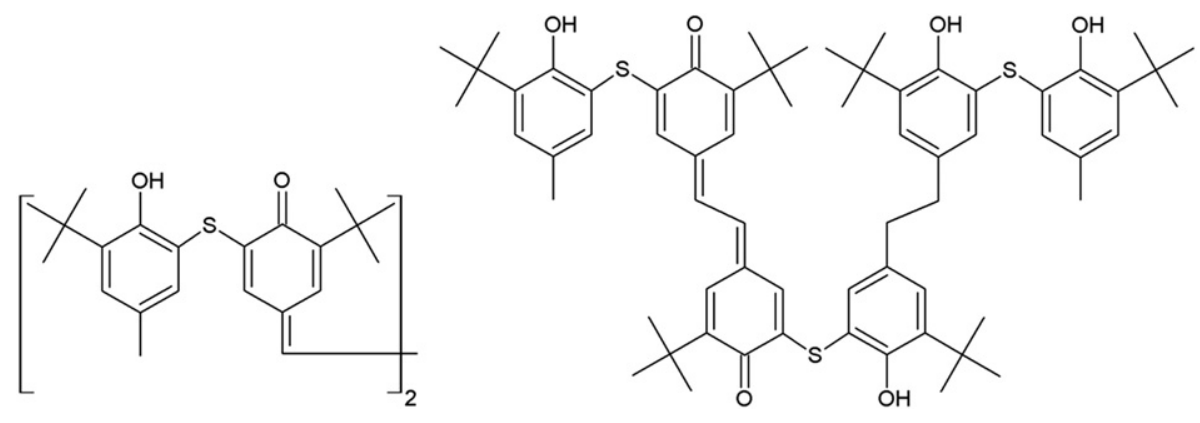

Scheme 1. Oligomeric species proposed by the literature $[13,21]$. 

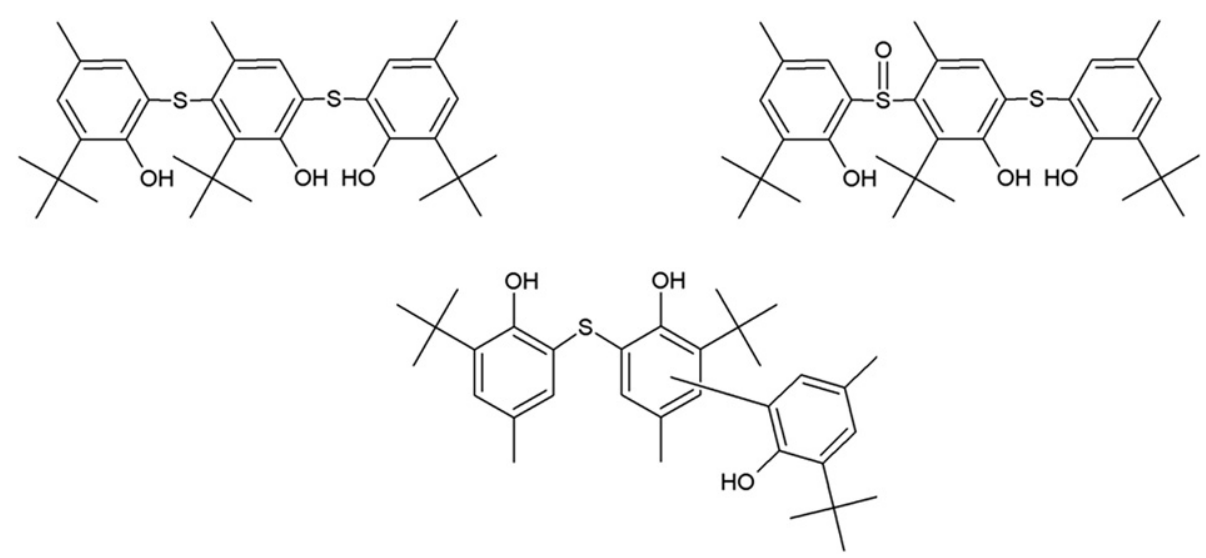

Scheme 2. Triphenolic structures proposed by Uhniat et al. [22].

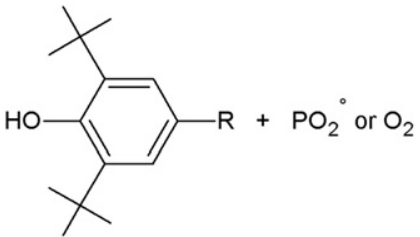

$(\mathrm{AH})$

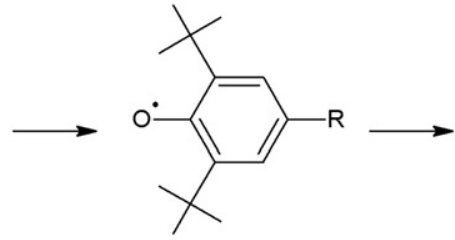

$\left(A R^{\circ}\right)$

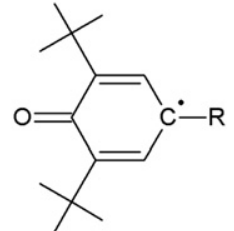

$\left(\mathrm{CR}^{\circ}\right)$

Scheme 3. Classical mechanism of the abstraction of the phenolic hydrogen.

$(\mathrm{XI}) \mathrm{AH}+\mathrm{O}_{2} \rightarrow$ oxidation products

$\left(k_{\mathrm{O}_{2}}\right)$

The reaction is expected to be second order:

$\frac{\mathrm{d}[\mathrm{AH}]}{\mathrm{d} t}=-f_{\mathrm{AH}} k_{\mathrm{O}_{2}}[\mathrm{AH}]\left[\mathrm{O}_{2}\right]$

being $f_{\mathrm{AH}}$ the phenol functionality, $k_{\mathrm{O}_{2}}$ the true second order rate constant, $\left[\mathrm{O}_{2}\right]$ the oxygen concentration in the solution and $[\mathrm{AH}]$ the residual stabiliser concentration. However, since in principle, the oxygen concentration is maintained constant, it can be assimilated to a first order process:

$\frac{\mathrm{d}[\mathrm{AH}]}{\mathrm{d} t}=-K[\mathrm{AH}]$

with $K=f_{\mathrm{AH}} k_{\mathrm{O}_{2}}\left[\mathrm{O}_{2}\right]$, i.e. $\ln [\mathrm{AH}]=\ln [\mathrm{AH}]_{0}-K t$.

The intensity of the chromatographic peak of the initial stabiliser decreases in an apparent first order process (Fig. 10), that seems to agree with our hypothesis. Second order rate constants $k_{\mathrm{O}_{2}}$ have been determined in various conditions. They are listed in Table 3 for all the antioxidants and ageing conditions under study. The oxygen concentrations were determined or estimated from the data reported in section 2.1, considering that oxygen concentration is the result of multiply the oxygen solubility by the oxygen pressure.

These results call for the following comments:

a) Concerning first the temperature effect: $k_{\mathrm{O}_{2}}$ increases with temperature. Its apparent activation energy is of the order of $100 \mathrm{~kJ} \mathrm{~mol}^{-1}$ and seems to display only a second order influence of structure.

b) Concerning the data relative to silicone oil, the hierarchy of $k_{\mathrm{O}_{2}}$ values is, at all temperatures:
The difference between AO5 and AO1, which differ only by the bisphenol bridge, is relatively subtle. AO4 is significantly more reactive that the bisphenols, that could seem surprising since, in this case, the phenolic function is partly regenerated through the formation of a cinnamic derivative [19].

c) Concerning the data relative to trichlorobenzene, the hierarchy of $k_{\mathrm{O}_{2}}$ values (at $90^{\circ} \mathrm{C}$ ) is:

$\mathrm{AO} 2>\mathrm{AO} 5>\mathrm{AO} 3$

Here, the thiobisphenol, of which the isomer AO1 was the less reactive in silicone oil, is the most reactive in trichlorobenzene.

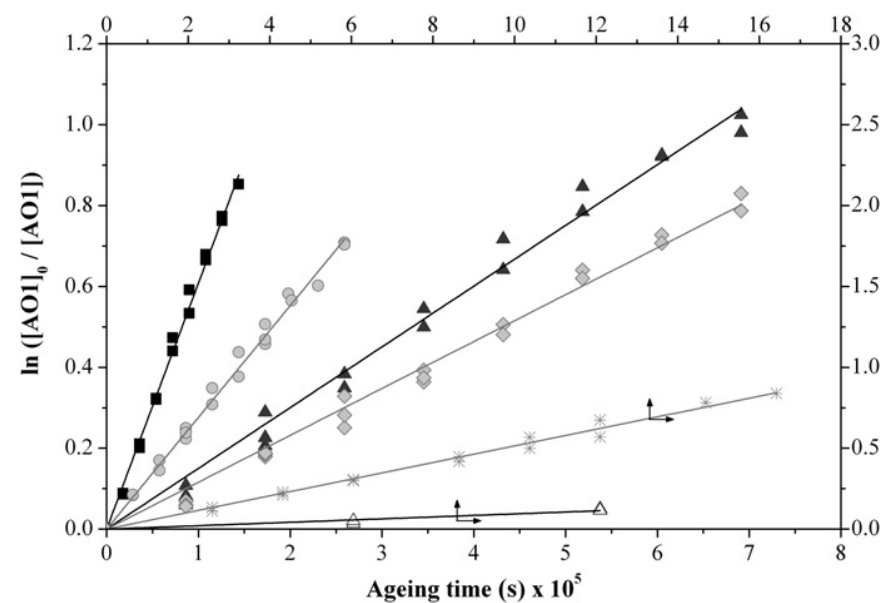

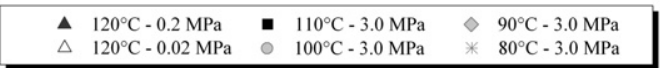

Fig. 10. First order plot for AO1 consumption at different experimental conditions. 
Table 3

Kinetic parameters of the antioxidant reaction with oxygen.

\begin{tabular}{|c|c|c|c|c|c|c|c|}
\hline \multirow{2}{*}{$\frac{\mathrm{T}-\mathrm{P}_{\text {Oxygen }}}{\text { Antioxidant }}$} & \multirow[t]{2}{*}{ Matrix } & \multirow[t]{2}{*}{$E_{\text {act }}$} & \multirow[t]{2}{*}{$\mathrm{S}_{\mathrm{O}_{2}}$ at $90{ }^{\circ} \mathrm{C}$} & \multicolumn{4}{|c|}{$k_{\mathrm{O}_{2}}\left(1 \mathrm{~mol}^{-1} \mathrm{~s}^{-1}\right) \times 10^{5}$} \\
\hline & & & & $80^{\circ} \mathrm{C}$ & $90{ }^{\circ} \mathrm{C}$ & $100{ }^{\circ} \mathrm{C}$ & $110^{\circ} \mathrm{C}$ \\
\hline & & $\overline{\left(\mathrm{kJ} \mathrm{mol}^{-1}\right)}$ & $\overline{\left(\mathrm{mol} \mathrm{l}^{-1} \mathrm{~Pa}^{-1}\right) \times 10^{8}}$ & $3.0 \mathrm{MPa}$ & $3.0 \mathrm{MPa}$ & $3.0 \mathrm{MPa}$ & 3.0 MPa \\
\hline $\mathrm{AO} 1$ & Silicone oil & 103 & 4.92 & 0.17 & 0.39 & 0.94 & 2.09 \\
\hline $\mathrm{AO} 2$ & 1,2,4-Trichlorobenzene & - & 1.06 & - & 7.78 & - & - \\
\hline $\mathrm{AO} 3$ & 1,2,4-Trichlorobenzene & - & 1.06 & - & 1.09 & - & - \\
\hline $\mathrm{AO} 4$ & Silicone oil & 98 & 4.92 & 0.94 & 1.04 & 3.50 & 7.79 \\
\hline \multirow[t]{2}{*}{ AO5 } & Silicone oil & 112 & 4.92 & 0.38 & 0.50 & 1.16 & 2.97 \\
\hline & 1,2,4-Trichlorobenzene & - & 1.06 & & 3.73 & & \\
\hline
\end{tabular}

d) Assuming that the hierarchy of reactivities is the same in silicone oil and trichlorobenzene, it comes:

$\mathrm{AO} 2>\mathrm{AO} 5>\mathrm{AO} 1$

The difference between $\mathrm{AO} 2$ and $\mathrm{AO} 5$ is presumably linked, at least partly, to the fact that $\mathrm{OH}$ group is less hindered in $\mathrm{AO} 2$ than in A05. The small difference between $\mathrm{AO} 5$ and $\mathrm{AO} 1$ can be attributed to a small difference between inductive effects of methylene and sulphur bridges.

e) $\mathrm{AO} 5$ appears more reactive than $\mathrm{AO}$, probably because its $\mathrm{OH}$ group is less hindered. It is tempting to conclude that the replacement of the methylene bridge by a propyl group one does not modify strongly the phenol reactivity.

Concerning now the practical aspects of this work, it can be first observed that the rate constant of the hindered phenol-oxygen reaction is more than one million times lower that the rate constant for the phenol-peroxy reaction [7]. Phenol-oxygen reactions will thus be negligible in many cases of thermal oxidation in air at atmospheric pressure $(0.02 \mathrm{MPa})$ but they will significantly contribute to antioxidant consumption at high oxygen pressures where they cannot be ignored in kinetic modelling.

Despite the difference of reactivity between $\mathrm{PO}_{2}{ }^{\circ}$ radicals and $\mathrm{O}_{2}$ (biradical), one can suppose that there are some similarities in their structure-reactivity relationships. It will be tried, in the future, to check these similarities.

\section{Conclusions}

Five hindered phenols used as polymer antioxidants have been exposed to molecular oxygen in inert solvents at temperatures ranging from 80 to $110{ }^{\circ} \mathrm{C}$ under $3.0 \mathrm{MPa}$ oxygen pressure. The structural transformations have been monitored by steric exclusion chromatography using various UV wavelengths for detection.

Silicone oil appears as the ideal matrix for such studies, owing to its very low UV absorption. However, certain antioxidants are almost insoluble in this medium, which led us to make certain experiments with trichlorobenzene with the inconvenient of its absorption in short-medium UV range.

All the stabilisers under study are destroyed by reaction with oxygen in a pseudo first order process corresponding to a true second order process of which the rate constant is of the order of $10^{-5} 1 \mathrm{~mol}^{-1} \mathrm{~s}^{-1}$ at $90{ }^{\circ} \mathrm{C}$.

The observed differences in reactivity are relatively small. However, they put in evidence a clear influence of steric hindrance. The reactivity of a $2,2^{\prime}$-thiobisphenol is almost the same as the one of the corresponding 2,2'-methylenebisphenol. For all the antioxidants, SEC measurements reveal the formation of oligomeric species containing both phenolic and quinone chromophores. Whereas thiobisphenols differ from alkylidene bisphenols by the fact that their oxidation leads to products containing three aromatic (or quinone) nuclei not seen in the case of alkylidene bisphenols or simple alkyl substituted monophenols. Some practical consequences of these results have been briefly discussed.

\section{Acknowledgements}

Financial support for this investigation has been provided by the Spanish Ministerio de Ciencia e Innovación through the "Ayudas de estancias de movilidad posdoctoral en el extranjero" Program.

\section{References}

[1] Pospíšil J. Mechanistic action of phenolic antioxidants in polymers. A review. Polym Degrad Stab 1988;20:181-202.

[2] Klemchuk PP, Horng PL. Transformation products of hindered phenolic antioxidants and colour development in polyolefins. Polym Degrad Stab 1991;34: 333-46.

[3] Scheirs J, Pospíšil J, O’Connor MJ, Bigger SW. Polymer durability: degradation, stabilization, and lifetime prediction. In: Clough RL, Billingham NC, Gillen KT, editors. Advances in chemistry series, vol. 249. Washington: American Chemical Society; 1996.

[4] Zweifel H. Stabilization of polymeric materials. Berlin: Springer-Verlag; 1998.

[5] Scott G. Atomospheric oxidation and antioxidants. New York: Elsevier Science; 1965

[6] Coquillat M, Verdu J, Colin X, Audouin L, Celina M. A kinetic evaluation of the thermal oxidation of a phenol stabilised polybutadiene. Polym Degrad Stab 2008;93:1689-94.

[7] Richaud E, Farcas F, Fayolle B, Audouin L, Verdu J. Accelerated ageing of polypropylene stabilized by phenolic antioxidants under high oxygen pressure. J Appl Polym Sci 2008;110:3313-21.

[8] Bolland J, Ten Have P. Kinetic studies in the chemistry of rubber and related materials. V. The inhibitory effect of phenolic compounds on the thermal oxidation of ethyl linoleate. Discuss Faraday Soc 1947;2:252-60.

[9] Altwicker ER. The chemistry of stable phenoxy radicals. Chem Rev 1967;67: 475-531.

[10] Shanina EL, Belyakov VA, Zaikov GE. Phenol antioxidant consumption rate in polypropylene. Polym Degrad Stab 1990;27:309-17.

[11] Jiráčková L, Pospíšil J. Antioxidants and stabilizers. Part LXVII: transformation of 4,4'-thiobis(2-methyl-6-tert-butylphenol) under conditions of inhibited autoxidation. Angew Makromol Chem 1978;66:95-104.

[12] Chasar DW. Bis(2-hydroxy-3-t-butyl-5-methylphenyl)sulphide, sulphoxide and sulphone as antioxidants for polypropylene. Polym Degrad Stab 1980;3: 121-5.

[13] Prusíková M, Kúdelka I, Brodilová J, Pospíšil J. Antioxidants and stabilisers. Part CV: activity of thiobisphenols as melt stabilizers. Polym Degrad Stab 1986;16:277-90.

[14] Son TT, Rotschová J, Prusíková M, Pospíšil J. Antioxidants and stabilisers. Part XCII: activity of 2,2'-thiobis(4,6-di-tert-butylphenol) as a hydroperoxide decomposer. A model study. Polym Degrad Stab 1983;5:205-13.

[15] Rotschová J, Son TT, Pospísil J. Antioxidants and stabilizers. Part C: decomposition of tert-butylhydroperoxide by polyolefin melt stabilizer 2,2'-thiobis(4,6-di-tert-butylphenol). Polym Degrad Stab 1985;12:181-90.

[16] Van Krevelen DW, Hoftyzer PJ. Properties of polymers. Amsterdam: Elsevier; 1976 [chapter 18]403-425.

[17] Richaud E. Ph.D. Thesis. Paris: ENSAM; 2006

[18] Navarro R, Audouin L, Verdu J. Reactions of antioxidants with molecular oxygen. Part I. 2,2'-methylene-bis(4-methyl-6-tert-butylphenol) in silicone matrix. Polym Degrad Stab 2011;96:220-5. 
[19] Navarro R, Audouin L, Verdu J. Reactions of antioxidants with molecular oxygen. Part II. Isooctyl-3-(3,5-di-tert-butyl-4-hydroxyphenyl)propionate in silicone matrix. Polym Degrad Stab 2011;96:965-73.

[20] Pospísil J, Nešpưrek S, Zweifel H. The role of quinone methides in thermostabilization of hydrocarbon polymers. I. Formation and reactivity of quinone methides. Polym Degrad Stab 1996;54:7-14.
[21] Pospíšil J. The key role of antioxidant transformation products in the stabilization mechanisms. A critical analysis. Polym Degrad Stab 1991;34:85-109.

[22] Uhniat M, Kudla S, Dziwiñski E, Sudol M. Stabilisation of LDPE cross-linked in the presence of peroxides III. Mass spectrometric study of chemical changes taking place in the n-octadecane-dicumyl peroxide-Irganox 1081 system. Polym Degrad Stab 2001;71:83-91. 